\title{
Research on the Problem of Carbon-Fiber Material in the Process of Strengthening the Small and Medium-sized Concrete Bridges 25
}

\author{
Teng-fei $\mathrm{HE}^{1 \mathrm{a}}$, Yong-feng $\mathrm{XU}^{1}$, Wen-juan $\mathrm{ZHAO}^{1}$, Ying-jie $\mathrm{ZHU}{ }^{1 \mathrm{~b}}$ \\ ${ }^{1}$ Hebei Institute of Architecture and Civil Engineering,Zhangjiakou 075024 China \\ aemai:email:304355574@qq.com, bemail:348128563@qq.com
}

\begin{abstract}
Keywords: Carbon-fiber materials;Small and medium-sized concrete bridge;concrete;construction Abstract. Using the carbon fiber material reinforced concrete structure technology is a kind of advanced technology which is widely used at present, But this kind of convenient and quick reinforcement technology is used in the large concrete structures more and more,On the contrary ,In the small and medium-sized concrete structures.Especially in some remote areas of small and medium-sized concrete bridges, the main problems in the process of reinforcement the research is not much, This article mainly aims at the problems of the concrete bridge structure in the process of research.This technology can be used to strengthen the construction of small and medium concrete bridge construction to provide reference.
\end{abstract}

\section{Introduction}

Carbon fiber material strengthening method is a kind of fiber reinforcement method, as a widely used in recent years, the concrete bridge reinforcement method, has been widely used in bridge designers and builders, and gradually become the focus of domestic and international civil engineering application research.

The use of carbon fiber reinforced concrete structure is a widely recognized advanced technology.In theory and practice,The majority of scientific research workers have paid a great effort,Make this technology in the field of civil engineering in the world has made great progress and great development,These studies are still some deficiencies for some practical problems.such as some large and medium projects or key projects to study more,but for some of the small and medium sized concrete bridges in remote areas be few studied.

At present, some small and medium sized concrete structure,Especially small concrete bridges and culverts in poor areas more reinforcement schemes apply large structures, that cause unnecessary waste.Because the low educational level of workers, technical training is not in place and lead to poor construction standards and reinforcing level difference, reducing the useful life after its restoration,from a future point of view, it will result in a loss of security and economy.

In view of the small and medium bridge using carbon fiber material for maintenance and reinforcement of the construction process not only to consider the durability of the repair,but also consider the economic and safety of the process.Although the carbon fiber material repair and reinforcement of the small concrete structures are often faced with a number of special circumstances, special problems and problems, but these problems have a certain commonality and consistency, we need to make a progress of thinking and research.These problems are mainly concentrated in the process of strengthening the surface of the members of the surface treatment, strengthening process and the fire prevention and the impact of adverse environment on the strengthening of the component.

\section{Strengthening the process of surface treatment of the reinforcing member}

These needs reinforcement in small concrete structures in remote areas, disrepair, harsh environment, damage and carbonization of concrete is relatively serious, exposed steel bars is relatively outstanding, rusted.So it is more difficult to deal with the surface of the bridge in the middle and small bridge in the remote area.So the situation is more complex due to the external carbon fiber material reinforcement technology is heavily dependent on the material and the structure of the surface paste 
the efficiency, so the surface treatment of such reinforcement components is the key to the success of the repair and reinforcement process.

The natural environment and an acidic substance and concrete itself contains an alkaline substance contained in a chemical reaction occurs complicate called carbonization or neutral.The carbonation of concrete is one of the most common and most direct factors causing the damage of concrete.With the further development of concrete carbonation, The $\mathrm{pH}$ value in the solution of the voids is further reduced, so that the passive film of the steel bar is gradually destroyed, and there may be water or oxide in the concrete,so that the concrete internal steel further corrosion, and finally make the concrete deterioration, expansion, broken, from the internal damage, the use of function gradually lost.

In some needed reinforcement in concrete structures,Especially for in the environment is relatively poor for small and medium bridges can often be found on the structure surface rust - brown patches or nubby points in the structure.

Especially for in the environment is relatively poor for small and medium bridges can often be found on the structure surface rust - brown patches or nubby points in the structure, scale like or is banded crack and crack have obvious exposed tendons and broken situation, these are due to concrete carbonation resulted.(is shown in Figure 1) if not treated in time or in common with other erosion conditions, it will lead to the rapid destruction of the structure.

(Figure 1)
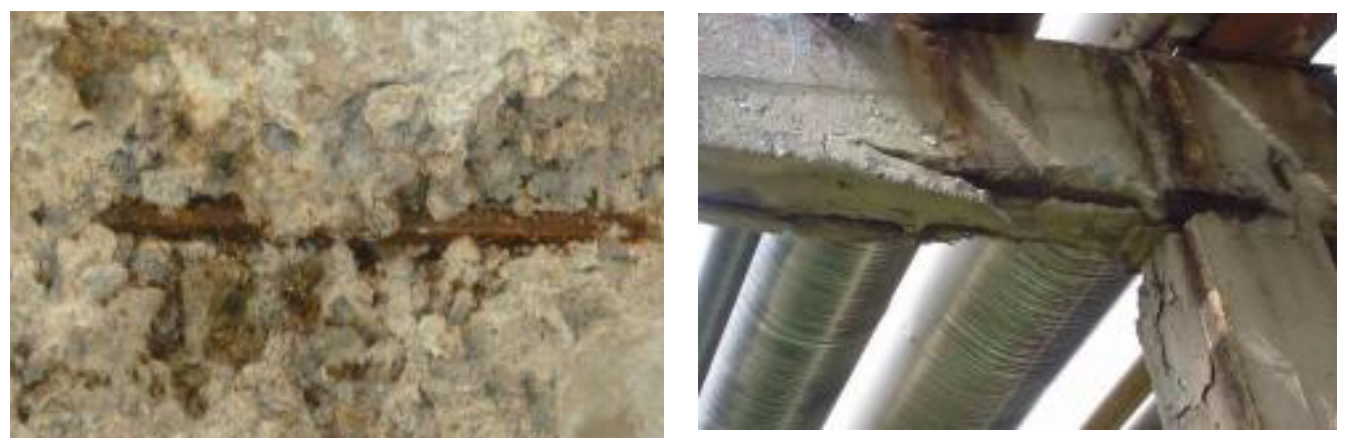

For the treatment of severe damage to the concrete, pro-construction needs the carbonization of the surface layer of the weak and broken layers layer cutting, no longer appear peeling, hollowing, cellular, deterioration and other phenomena.Treatment of large areas of degraded layer requires special attention,

Epoxy mortar shall be used immediately after removal of the deterioration layer,

In front of the repair construction also need to clean the surface of the concrete, not too much is stained with dirt stained and sand, for relatively small area of the sag can be directly by leveling glue the smooth operation.Treatment process should be gradually cut, avoid blind pursuit, caused by reinforcement component surface and internal further damage, resulting in greater losses.Also for the repair and reinforcement of heating, dehumidifying operation, avoid and repairing and strengthening operations at odds of wet operations, to ensure the reinforcement component and the near environment of dry.

According to the relevant literature, the crystalline water released from the carbonation of concrete is caused by the shrinkage deformation of concrete.

All the irreversible are shrinkage ${ }^{[1]}$,If the carbonation shrinkage is carried out under the constraint conditions, the concrete surface cracks can be initiated and the concrete cracks will increase the possibility of contact with the air and other harmful components, and further increase the possibility of carbonation,At the same time some originally in the alkaline environment of the concrete relatively stable complex in the process of carbonation of concrete caused part of chloride ion release, caused by chlorine salt erosion, thus further corrosion. And the corrosion of the steel will not only affect the concrete components.

For the treatment of corroded steel bar, it is time to use the rust inhibitor, to prevent the bare corrosion of steel bar further corrosion.In the construction, the use of Corrosion Inhibitor Mtgrating 
repair,The main use of FerroGard Sika more than 903 functional inhibitors.It will be dealt with after the damaged concrete, corroded reinforced for processing,After treatment of damaged concrete, the corrosion of steel bar is processed,First, the corrosion resistance of the coating on the surface of the concrete to be protected,After the surface of the concrete dry 2-6 to second hours for the 2 time,Then wait 2 to 6 hours for the third time,After the spraying, the test needs to spray the Department whether it is sprayed or not.Need to pay attention to the way the water immersion in the spraying process, rain and fog and 5 level gale days should stop the construction.

\section{The strengthening process and the fire prevention}

Carbon fiber material in the case of isolated oxygen has very good high temperature performance, the highest up to $2000^{\circ} \mathrm{C}$, and it is the sublimation of the temperature at $3650^{\circ} \mathrm{C}$.If in an aerobic environment, the oxidation of carbon fiber material is very obvious at $400^{\circ} \mathrm{C}$, If exposed to the air above $600^{\circ} \mathrm{C}$, the oxidation rate and the intensity of oxidation are very large, It is indicated that the carbon fiber material can be completely oxidized in ten minutes ${ }^{[2]}$.If there is no protective measures for the carbon fiber material used in the construction, the fire resistance of the strengthened members is very poor, it is difficult to reach the corresponding fire resistance grade, which brings a great security risk to the reinforced component.Bisby $\mathrm{L} \mathrm{A}^{[3]}$ and other. In the article, the expounds the fire resistance limit of the reinforced structure using FRP , the lack of necessary scientific basis In accordance with the United States promulgated by the United States $<$ Guide For the Design and Construction of Externally Bonded FRP System For Strengthening Concrete Structures> general restrictions on carbon fiber materials to improve the bearing capacity of the members to obtain the standard requirements of the fire resistance limit Although it can ensure its security, but also caused a great waste.

Small and medium sized construction structure reinforcement process, because of the narrow space, a variety of tasks sharing site, ignition system imperfect, the construction workers safety consciousness weak and other reasons is extremely easy to cause a fire.Meanwhile, if a fire occurs,epoxy resin adhesive paste used will produce bad effect greatly.Action at high temperatures, with the oxidized carbon fiber materials, steel and concrete of lower strength, reinforcing security member will bring a huge risk.Even though the small fire accident can not directly destroy the reinforcement structure,But in the role of high temperature, carbon fiber material, epoxy resin, concrete, mechanical properties of the steel will have different degrees of reduction, thereby reducing the service life of the strengthening of the reinforcement, the potential safety hazards, and it is possible to bring greater losses in the future.

According to the relevant provisions of $<$ the technical regulations on carbon-fiber material using to reinforce and repair concrete construction $>\left(\right.$ CECS146:2003) ${ }^{[4]}$,We find that the specific measures are only to do the principle of the provisions, and there is no qualitative and quantitative expression,and no specific fire protection requirements of the building to choose the appropriate fire protection measures in order to meet the requirements of the fire rating.Currently only the United States has provided some design and measures of specific practices, but too conservative.At present, the design and construction of fire protection design and construction in large and medium sized projects are adopted,But for small and medium projects, the specific measures to improve the fire resistance of this kind of structure have practical significance.

In the design, as far as possible to the fire prevention requirements, According to the standard design of the simplified design procedures in the local conditions. Under normal circumstances the amount of reinforcement 22.5\%, The load ratio is greater than 0.5 and the thickness of the fire retardant coating can be satisfied as well as the fire resistance requirements of the simple supported beam with $10 \mathrm{~mm}$. The actual load ratio is no more than 0.5 , and the thickness of the coating is chosen according to the following table (is shown in table 1) ${ }^{[5]}$. 
Table 1 Fireproof coating thickness gauge

\begin{tabular}{cccc}
\hline Flexural reinforcement & $20 \%$ & $30 \%$ & $40 \%$ \\
\hline $\begin{array}{c}\text { Fire paint thickness } \\
\text { required to achieve a } \\
\text { level of fire resistance }\end{array}$ & $10 \mathrm{~mm}$ & $15 \mathrm{~mm}$ & $20 \mathrm{~mm}$ \\
\hline Applicable to non-intumescent fire retardant coating and the actual load ratio is not more than 0.5 \\
\hline
\end{tabular}

Appropriate increase in the height of the beam side of the fire paint, taking into account the cost can be appropriate to increase the proportion of key fire prevention measures, while the cement mortar fire.

At present not only in small-scale projects in the construction process, and even many of our large-scale construction sites also exist for the prevention of fire ignore the situation, Compressiontime limit for a project, Covet convenient,Saving material

and so many reasons is an important reason for some of the construction site of fire, the more important reason is from management to the team do not pay attention to.The research shows that no matter how large area of fire or small area, will be the construction of the building damage, some damage is difficult to find with experience, after a simple treatment of the burned buildings may be in the future to form a safety hazard, resulting in a safety accident.So in the construction, strictly comply with the relevant provisions of the <Code for fire protection design of buildings $>$ (GB50016 2006).In strict accordance with the construction manual and construction standards system construction ,Do technical disclosure and standardize the field capacity, set up specialized security staff responsible for construction supervision, strict construction site fire approval system.

\section{The impact of the harsh environment on the strengthening of the component}

Most of the small and medium bridges need to be repaired in the remote areas of the environment, therefore, it is necessary to consider the impact of severe environment on the repair and reinforcement, so as to facilitate the observation and maintenance.

The effect of temperature change. Temperature changes may lead to carbon fiber materials, adhesives and concrete due to different collision rate between a tear of the carbon fiber material ,Under the action of load, the resistance to the strain (creep resistance) is too dependent on the temperature, and the effect of the adhesive,In high temperature, it may cause the degradation of the adhesive, resulting in the loss of carbon fiber material.

The effect of the damp environment. The excessive moisture of the environment will cause the increase of the content of free water in the reinforcement member, which may cause the change of the matrix properties. The excessive moisture of the environment will cause the increase of the content of free water in the reinforcement member, which may cause the change of the matrix properties,

Moisture can decrease the elastic modulus of the epoxy resin, and make the strength decrease obviously when the temperature rises ${ }^{[6]}$,Some irreversible changes can also lead to the physical and mechanical properties have great degradation.

The effect of Strong corrosive environment.In some regions because of environmental pollution, in a strong corrosive environment, this will make the matrix and fiber surface produces a variety of other reaction, obvious stress corrosion effect, thereby reducing the strength of the fiber material.In addition, the maintenance and reinforcement of carbon fiber materials to improve the corrosion resistance of the research shows that carbon fiber materials and can not directly improve their corrosion resistance, but for some corrosive elements, such as $\mathrm{Cl}^{-}, \mathrm{SO}_{4}{ }^{2-}$, etc. played a role in blocking, so as to play a certain role in anti-corrosion,But we should know is to enhance the ability of anti corrosion degree is related to the types of binder and adhesive worried if ignore binder alone fiber material is not to improve component corrosion resistance to any role, so the choice of binder to improve component corrosion is particularly important.

Use of carbon fiber materials in the process of bridge reinforcement of concrete not only can appear the problems described herein ${ }^{[7]}$, but these problems are in the process of small and medium 
sized concrete bridge reinforcement or easily neglected problems easily.In this paper, some solutions are put forward, which can provide reference for the construction of small and medium concrete bridges in the future. The future construction is more safe, convenient and quick.

\section{Acknowledgements}

This work was financially supported by Hebei Province College of science and technology research Youth Fund.

\section{References}

[1] Luo-shu GONG,Chun-fu LIU ,The durability of concrete repair and protection.BEIJING: China Building Industry Press, 1990 in chinese

[2] Long-gui TANG.Oxidation resistance of carbon fiber[J].Journal of high school chemistry ,1995,16(8): 1301-1305 in chinese

[3] Bisby L A,Kodur V K R,Green M F. Mondeling the behavior of fiber reinforced polymer-confined concrete columus exposed to fire[J].Journal of Composites for Construction ,ASCE,2005,9(1):15-24

[4] The technical regulations on carbon-fiber material using to reinforce and repair concrete construction[S]. China Planning Press,2003; in chinese

[5] Fen-tao LIU.Study on high temperature performance of concrete beam strengthened with carbon fiber sheet[D]. Doctoral Dissertation of South China University of Technology,2010; in chinese

[6] D.Hull.An introduction to composite materials[M].BEIJING,China building industry press1989

[7] Jian-guo WANG.The construction application of carbon fiber reinforced plastics[J]Gansu Journal of science and technology,2003(11); in chinese 